\title{
THE SOCIETY'S PRIZES
}

At the Annual Meeting of the Society held at Bethlehem, the Council adopted a report received from its Committee on the Reorganization of the Society's prizes, composed of Professors R. D. Carmichael (Chairman), Abraham Cohen, and H. H. Mitchell. The conditions of award, as established by action of the Council and Board of Trustees in accordance with these recommendations, will govern future procedure.

One reason for the reorganization was the insurmountable difficulty found by earlier committees of award of the Bôcher Memorial Prize in reaching a confident conclusion when an award is made without restriction of subject matter for memoirs considered. Another is that through the generosity of $\mathrm{Mr}$. Charles A. Cole the funds in honor of his father, Professor Frank Nelson Cole, have been doubled.

It was decided to establish three prizes of two hundred dollars $(\$ 200)$ each, to limit the field for each prize, and to award them at five-year intervals in accordance with the following schedule:

(1) The Bôcher Prize in Analysis to be awarded at the end of 1933 for papers in analysis published during the years 1928 to 1932 inclusive;

(2) The Cole Prize in Algebra to be awarded at the end of 1934 for papers published during the years 1929-33;

(3) The Cole Prize in the Theory of Numbers to be awarded at the end of 1931 for papers published during the years 192630 inclusive.

If the committee on award finds no memoir of outstanding merit at the time appointed for a given award, it will report this fact to the Council; the Council concurring, no award shall be made at that time.

The following conditions for eligibility have been adopted:

1. A memoir to be eligible for consideration must have been published in the appropriate interval of time in a journal on the editorial board of which the American Mathematical Society 
was officially represented at the time of publication of the memoir.

2. The author at the time of publication of the memoir must have been a member of the American Mathematical Society.

3. The author at the time of publication of the memoir must have been not more than fifty years of age.

4. No dissertation shall be eligible for any one of the prizes.

5. No author who has once received a particular prize shall again be awarded the same prize.

6. No paper shall be eligible for more than one prize.

The Bôcher Prize in Analysis is a continuation of the Bôcher Memorial Prize (see this Bulletin, vol. 28, p. 42). The conditions of award have, however, been changed so that the subject matter is now restricted to analysis; on the other hand, the place of publication is no longer restricted to the Transactions of this Society, but may be any journal on whose editorial board the Society is represented. The two Cole prizes are in many respects a continuation of the Cole Prize in Algebra (see this Bulletin, vol. 29, p. 14), but are no longer restricted to papers offered in competition on announced topics.

The report of the Committee stressed the desirability of having prizes also in geometry and in applied mathematics. Such prizes cannot be established until special funds for them have been secured. It is hoped that the Society may soon be in a position to announce these additional awards so that one prize may be given each year.

R. G. RICHARDSON, Secretary 